\title{
ERRATUM
}

\section{The Biggest Estate on Earth: How Aborigines Made Australia - ERRATUM}

Bill Gammage Allen \& Unwin, Sydney, 2011, 434 pp., ISBN 9781743311325

Reviewed by Debbie Prescott, Angela Colliver \& Sandra Nichols, Education for Sustainability. Email sandra@educationforsustainability.com.au

doi: 10.1017/aee.2015.42, Published online by Cambridge University Press, 21st December 2015

The following errors have been noted in the above mentioned article. The publisher regrets this error and sincerely apologises for any inconvenience caused:

On page 283, under the heading 'The Biggest Estate on Earth: How Aborigines Made Australia':

'Reviewed by Debbie Prescott, Angela Colliver \& Sandra Nichols, Education for Sustainability. Email sandra@educationforsustainability.com.au'

Should read:

'Reviewed by Sandra Nichols, Education for

Sustainability. Email sandra@educationforsustainability.com.au'

And in the contents, under the heading 'The Biggest Estate on Earth: How Aborigines Made Australia':

'Reviewed by Debbie Prescott, Angela Colliver \& Sandra Nichols'

Should read:

'Reviewed by Sandra Nichols'

\section{Reference}

Sandra Nichols (2015). Review of 'The Biggest Estate on Earth: How Aborigines Made Australia' Australian Journal of Environmental Education, 31, pp 283-285. doi:10.1017/aee.2015.42. 